\title{
IGF-II and IGF Binding Protein (IGFBP-1, IGFBP-3) Gene Expression in Fetal Rhesus Monkey Tissues during the Second and Third Trimesters
}

\author{
CHANG I. LEE, ORLY GOLDSTEIN, VICTOR K.M. HAN, AND ALICE F. TARANTAL \\ California Regional Primate Research Center [C.I.L., O.G., A.F.T.] and Department of Pediatrics \\ [A.F.T.], University of California, Davis, California 95616, U.S.A.; and MRC Group in Fetal and \\ Neonatal Health and Development, Lawson Research Institute, University of Western Ontario, London, \\ Canada, N6A4V2 [V.K.M.H.]
}

\begin{abstract}
The IGF system is a key modulator of somatic fetal growth. Studies with human fetal tissues have shown a specific spatial and temporal pattern of expression of IGF and IGF binding protein (IGFBP) mRNAs, but have been limited to defined periods during gestation (i.e. $8-20 \mathrm{wk}$ gestation) because of tissue availability. To fully assess the role of these peptides in the primate growth process, a longitudinal study was conducted that focused on the expression of IGF-II and IGFBP-1 and IGFBP-3 genes in the rhesus monkey (Macaca mulatta). Liver, kidney, brain, and lung were collected from rhesus monkey fetuses approximately every $2 \mathrm{wk}$ from 65 (early second trimester) through $150 \mathrm{~d}$ gestation (term $165 \pm 10 \mathrm{~d})(n=50)$, then processed for in situ hybridization using radiolabeled human cDNAs. IGF-II mRNA was abundantly expressed in fetal kidney (maturing glomerulus, supporting mesenchyme, cells of the developing nephrons), liver (hepatocytes), cerebral cortex (choroid
\end{abstract}

plexus, capillaries), and lung (blood vessels, connective tissues, lamina propria, cartilage framework). IGFBP-1 was expressed only in the hepatocytes and IGFBP-3 mRNA was modestly expressed within the kidney (developing nephrons, collecting system mesenchyme), and liver (hepatocytes). These studies have shown that (1) IGF-II, IGFBP-1, and IGFBP-3 are expressed in specific cell types of the fetal monkey indicating a paracrine/autocrine role during development; (2) changes in IGF-II and IGFBP mRNA expression occur with advancing gestation; and (3) fetal monkey tissues express IGF-II and IGFBPs in a similar manner when compared with the human fetus. (Pediatr Res 49: 379-387, 2001)

IGFBP, IGF binding protein
Fetal growth is a complex process involving multiple maternal and fetal factors, and a key modulator of somatic fetal growth is the IGF system (1-3). IGFs have been shown to be directly involved in growth and differentiation of the fetus as evidenced by reduction in fetal size as a result of mutation of either IGF genes or receptors (4-6). Both IGF-I and IGF-II are ubiquitously distributed peptides that exert potent mitogenic and differentiation effects on many cell types, as well as insulin-like effects on various metabolic and glucose and amino acid transport processes $(7,8)$. These biologic effects are the result of interactions of both IGF-I and IGF-II with their tyrosine kinase receptor, the type 1 IGF receptor (9).

Received May 9, 2000; accepted November 10, 2000.

Correspondence and reprint requests: Alice F. Tarantal, Ph.D., California Regional Primate Research Center, Pedrick and Hutchison Roads, University of California, Davis, CA 95616-8542, U.S.A.

Supported by National Institutes of Health (NIH) grants \#DK53711, \#DK49317, \#AI32266, and \#RR00169.
IGFBPs are a family of proteins that possess unique biologic properties, and are well-described modulators of IGF activity at the cellular level $(7,10,11)$. In the mammalian fetus, circulating concentrations of IGFs increase during gestation, although only a small percentage of the circulating IGFs are free in the circulation (unbound) due to high concentrations of IGFBPs (9). The functions of the IGFBPs include (1) to increase the circulating half-life of IGFs, (2), to transport IGFs in the circulation and within the vascular compartments, (3), to localize IGFs to specific cell types, and (4) to modulate growth-promoting actions (12). The interaction between IGFs and the predominant circulating IGFBP, IGFBP-3, is a delicate balance between the inhibitory or potentiating effects of soluble IGFBP-3 versus cell-associated IGFBP-3. Because IGFBPs can associate with cell membranes and elements of extracellular matrix, it has been proposed that a partitioning of available IGFs between the receptor and either membranebound, matrix-bound, or soluble IGFBPs is a potential mech- 
anism for regulating IGF bioavailability (12). IGFBP-3, for example, has been proposed to have a different affinity for IGF-I in fluids versus in a membrane-bound state. Further, evidence that the IGFBPs facilitate the translocation of IGFs across endothelial boundaries supports an endocrine role for the IGFs, whereas the expression of the IGFs and the type 1 IGF receptor in fetal tissues suggests that actions are also exerted locally, either on cells of synthesis (an autocrine action) or those in close proximity (paracrine role). Experimental findings have suggested that, although many fetal cells may possess IGF receptors and are responsive to exogenous IGF, they are not necessarily capable of synthesis (13).

The fetal/neonatal monkey has been used extensively as a model for the human because of developmental similarities. These similarities include spatial and temporal patterns of organ development, placental structure, length of gestation, growth characteristics, and hematopoietic and immune system ontogeny (14-21). Our prior studies have established normative reference values for circulating IGF-I, IGF-II, and IGFBP-3 in both the maternal and fetal compartments, characterized the IGFBP profiles during the second and third trimesters, and described the different immunoreactive forms of IGFBP-3 in both maternal and fetal serum (16). We have also shown that significant reductions in circulating IGF-I and elevated immunoreactive levels of IGFBP-3 occur in experimentally growth-restricted monkey fetuses (19), and that the direct administration of IGF-I to fetal monkeys has somatic, growth, and immune system effects (18).

Essential to the understanding of growth regulation and restriction is the spatial and temporal pattern of expression of the IGF and IGFBP genes. Studies with human fetal tissues have delineated expression patterns, but have been limited to brief periods during gestation (22-31). Thus, the goal of this study was to conduct a longitudinal analysis of select nonhuman primate specimens (liver, kidney, brain, lung) to assess IGF-II, IGFBP-1, and IGFBP-3 gene expression during the second and third trimesters, and to compare findings to those reported for human fetuses during early gestation. These studies have shown that the expression of IGF-II and the IGFBPs is limited to specific cell types during gestation, and that expression patterns are similar to the human fetus.

\section{MATERIALS AND METHODS}

\section{Animals}

All animal procedures conformed to the requirements of the Animal Welfare Act and protocols were approved before implementation by the Institutional Animal Use and Care Administrative Advisory Committee at the University of California at Davis. Activities related to animal care (diet, housing) were performed as per standard California Regional Primate Research Center operating procedures. Normally cycling, adult female rhesus macaques (Macaca mulatta) with a history of prior pregnancy were bred and identified as pregnant according to established methods $(n=50)$ (17). Pregnancy in the rhesus monkey is divided into trimesters by $55-\mathrm{d}$ increments with $0-55 \mathrm{~d}$ gestation representing the first trimester, 56-110 d gestation representing the second, and 111-165 d gestation representing the third trimester (term $165 \pm 10 \mathrm{~d}$ gestation) (16). For these studies, a total of 50 fetuses were included, with the number of fetuses available for each of the gestational ages ranging from 3 to 10 (Tables $1-4$ ).

\section{Fetal Tissue Harvests}

Fetuses were sonographically evaluated to confirm normal growth and viability during gestation (17), then delivered by hysterotomy approximately every 2 wk from 65 (early second trimester) to 150 (term) d gestation. Complete tissue harvests were performed using standard techniques (19). Total body weights and measures were assessed, then all organs were removed and weighed including the thymus, spleen, liver, lymph nodes, pancreas, adrenals, kidneys, gonads, small and large intestine, heart, lung, brain, muscle, and bone. Representative sections of all tissues were formalin-fixed, paraffinembedded, sectioned at $6 \mu \mathrm{m}$, and stained with hematoxylin and eosin for histopathologic analyses. Select tissues (liver,

Table 1. Cellular localization of IGF-II, IGFBP-1, and IGFBP-3 in fetal rhesus monkey liver from 65 to $150 \mathrm{~d}$ gestation

\begin{tabular}{clccc}
\hline Cell type & \multicolumn{1}{c}{ Gestational ages* } & IGF-II $\dagger$ & IGFBP-1 + IGFBP-3§ \\
\hline Hepatocytes & Second trimester $(65,80,100)$ & ++++ & + & ++ \\
& Third trimester $(130,140,150)$ & + & - & - \\
Supporting & Second trimester $(65,80,100)$ & - & - & - \\
connective tissue & Third trimester $(130,140,150)$ & - & - & - \\
Endothelial cells & Second trimester $(65,80,100)$ & - & - \\
- arteries & Third trimester $(130,140,150)$ & - & - \\
Endothelial cells & Second trimester $(65,80,100)$ & - & - \\
- portal vein & Third trimester $(130,140,150)$ & - & - \\
Endothelial cells & Second trimester $(65,80,100)$ & - & -
\end{tabular}

Kupffer cells were not definitively identified, thus these cells were not included.

* No significant differences were detected in IGF-II, IGFBP-1, and IGFBP-3 mRNA expression when comparing 65, 80, and $100 \mathrm{~d}$ gestation (second trimester), and when comparing 130,140, and $150 \mathrm{~d}$ gestation (third trimester), therefore these gestational ages were grouped by trimester. $(-)=$ no evidence of expression; $(+)=$ weak; $(++)=$ modest; $(+++)=$ moderate; $(++++)=$ strong $($ see text $)$.

$\dagger n=6$ (second trimester), $n=10$ (third trimester).

$+n=5$ (second trimester), $n=10$ (third trimester).

$\S n=6$ (second trimester), $n=9$ (third trimester). 
Table 2. Cellular localization of IGF-II, IGFBP-1, and IGFBP-3 in fetal rhesus monkey kidney from 65 to $150 d$ gestation

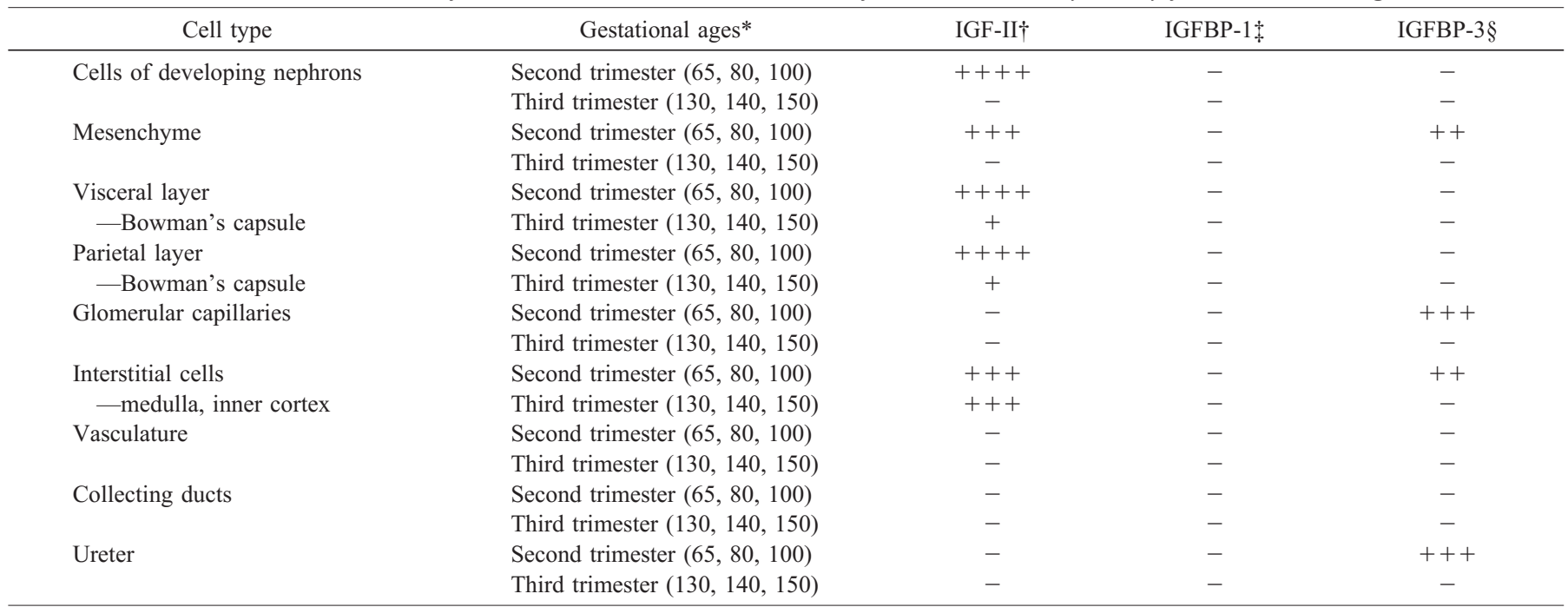

* No significant differences were detected in IGF-II, IGFBP-1, and IGFBP-3 mRNA expression when comparing 65, 80, and 100 d gestation (second trimester), and when comparing 130,140, and $150 \mathrm{~d}$ gestation (third trimester), therefore these gestational ages were grouped by trimester. $(-)=$ no evidence of expression; $(+)=$ weak; $(++)=$ modest; $(+++)=$ moderate; $(++++)=$ strong $($ see text).

$\dagger n=6$ (second trimester), $n=9$ (third trimester).

$\ddagger n=6$ (second trimester), $n=8$ (third trimester).

$\S n=6$ (second trimester), $n=10$ (third trimester).

Table 3. Cellular localization of IGF-II and IGFBP-1 in fetal rhesus monkey cerebral cortex from 65 to 150 d gestation

\begin{tabular}{llcc}
\hline \multicolumn{1}{c}{ Cell type } & \multicolumn{1}{c}{ Gestational ages* } & IGF-II $\dagger$ & IGFBP-1+ \\
\hline Neuroglia $\S$ & Second trimester $(65,80,100)$ & - & - \\
& Third trimester $(130,140,150)$ & - & - \\
Ependymal cells & Second trimester $(65,80,100)$ & - & - \\
& Third trimester $(130,140,150)$ & - & - \\
\multirow{2}{*}{ Choroid Plexus } & Second trimester $(65,80,100)$ & ++++ & - \\
& Third trimester $(130,140,150)$ & +++ & - \\
Meninges & Second trimester $(65,80,100)$ & ++++ & - \\
& Third trimester $(130,140,150)$ & +++ & - \\
Capillaries & Second trimester $(65,80,100)$ & +++ & - \\
& Third trimester $(130,140,150)$ & +++ & - \\
\hline
\end{tabular}

* No significant differences were detected in IGF-II and IGFBP-1 mRNA expression when comparing 65, 80, and $100 \mathrm{~d}$ gestation (second trimester), and when comparing 130,140, and $150 \mathrm{~d}$ gestation (third trimester), therefore these gestational ages were grouped by trimester. $(-)=$ no evidence of expression; $(+)=$ weak $(++)=$ modest $(+++)=$ moderate $(++++)=$ strong $($ see text).

$\dagger n=5$ (second trimester), $n=10$ (third trimester).

$\ddagger n=3$ (second trimester), $n=5$ (third trimester).

$\S$ Specific cell types not identified for neuroglia, special stains required.

kidney, cerebral cortex, lung) were assessed for IGF-II, IGFBP-1, and IGFBP-3 expression.

\section{In situ Hybridization}

In situ hybridization was performed according to the methods of Coulter and Han (32) using ${ }^{35}$ S-labeled antisense and sense IGF-II, IGFBP-1, and IGFBP-3 RNA (cRNA) probes generously provided by Drs. Martin Jansen (University of Utrecht, The Netherlands) and Shunichi Shimasaki (Scripps Clinic, San Diego, CA, U.S.A.). Briefly, tissues were fixed in $10 \%$ buffered formalin or $4 \%$ paraformaldehyde and processed using standard methods. Tissue sections were mounted on Superfrost slides, deparaffinized, rehydrated in descending eth-
Table 4. Cellular localization of IGF-II and IGFBP-1 in fetal rhesus monkey lung from 65 to 150 d gestation

\begin{tabular}{|c|c|c|c|}
\hline Cell type & Gestational age* & IGF-II $\dagger$ & IGFBP-1† \\
\hline \multirow[t]{2}{*}{ Respiratory epithelium } & Second trimester $(65,80,100)$ & + & - \\
\hline & Third trimester $(130,140,150)$ & + & - \\
\hline \multirow[t]{2}{*}{ Smooth muscle } & Second trimester $(65,80,100)$ & + & - \\
\hline & Third trimester $(130,140,150)$ & + & - \\
\hline \multirow[t]{2}{*}{ Lamina propria } & Second trimester $(65,80,100)$ & +++ & - \\
\hline & Third trimester $(130,140,150)$ & ++ & - \\
\hline \multirow[t]{2}{*}{ Connective tissue } & Second trimester $(65,80,100)$ & +++ & - \\
\hline & Third trimester $(130,140,150)$ & ++ & - \\
\hline \multirow[t]{2}{*}{ Cartilage framework } & Second trimester $(65,80,100)$ & +++ & - \\
\hline & Third trimester $(130,140,150)$ & ++ & - \\
\hline \multirow[t]{2}{*}{ Arterial endothelial cells } & Second trimester $(65,80,100)$ & ++++ & - \\
\hline & Third trimester $(130,140,150)$ & +++ & - \\
\hline \multirow[t]{2}{*}{ Blood vessels } & Second trimester $(65,80,100)$ & +++ & - \\
\hline & Third trimester $(130,140,150)$ & +++ & - \\
\hline \multirow[t]{2}{*}{ Submucosa } & Second trimester $(65,80,100)$ & - & - \\
\hline & Third trimester $(130,140,150)$ & - & - \\
\hline \multirow[t]{2}{*}{ Epithelium-alveoli } & Second trimester $(65,80,100)$ & - & - \\
\hline & Third trimester $(130,140,150)$ & - & - \\
\hline \multirow[t]{2}{*}{ Capillaries } & Second trimester $(65,80,100)$ & - & - \\
\hline & Third trimester $(130,140,150)$ & - & - \\
\hline
\end{tabular}

* No significant differences were detected in IGF-II and IGFBP-1 mRNA expression when comparing 65, 80, and $100 \mathrm{~d}$ gestation (second trimester), and when comparing 130,140, and $150 \mathrm{~d}$ gestation (third trimester), therefore these gestational ages were grouped by trimester. $(-)=$ no evidence of expression; $(+)=$ weak; $(++)=$ modest $(+++)=$ moderate; $(++++)=$ strong $($ see text).

$\dagger n=5$ (second trimester), $n=10$ (third trimester).

$\$ n=3$ (second trimester), $n=10$ (third trimester).

anol series $(100 \%, 90 \%, 70 \%)$, and incubated in the following solutions: $0.2 \%$ Triton X-100 in PBS for $1 \mathrm{~h}$, proteinase-K (1 $\mu \mathrm{g} / \mathrm{mL})$ for $30 \mathrm{~min}$, and acetic anhydride $(0.25 \%)$ in triethanolamine buffer (Sigma Chemical Co., St. Louis, MO, U.S.A.). Sections were then dehydrated in ascending ethanol series, prehybridized with $1 \times$ hybridization buffer at $55^{\circ} \mathrm{C}$, then 
hybridized with the chosen cRNA probe $\left(1 \times 10^{6} \mathrm{cpm} / \mathrm{slide}\right)$. After treatment and washing, sections were dehydrated in ascending ethanol series and exposed to x-ray film (Biomax, Kodak Laboratories, Rochester, NY, U.S.A.) overnight at room temperature. Slides were coated with photoemulsion (NTB-3 nuclear track emulsion, Kodak Laboratories) and exposed at $4^{\circ} \mathrm{C}$ for $1-2 \mathrm{wk}$. Slides were developed, fixed, washed, and stained with hematoxylin and eosin.

\section{Scoring System}

IGF-II, IGFBP-1, and IGFBP-3 gene expression was examined under bright-field and dark-field microscopy. Based upon previously published descriptions, and for the purpose of analysis of fetal tissues, we devised a semiquantitative assessment of gene expression that focused on the relative abundance of expression using a 0 to $4+$ scoring system as follows: $(-)=$ no evidence of expression; $(+)=$ weak expression, $(++)=$ modest expression, $(+++)=$ moderate expression, and $(++++)=$ strong levels of expression.

\section{RESULTS}

Fetal liver was assessed for IGF-II (Fig. 1), IGFBP-1 (Fig. 2), and IGFBP-3 (Fig. 3) gene expression; fetal kidney for IGF-II (Fig. 4), IGFBP-1, and IGFBP-3 (Fig. 5) gene expression; fetal cerebral cortex for IGF-II (Fig. 6) and IGFBP-1 gene expression; and fetal lung for IGF-II (Fig. 7) and IGFBP-1 gene expression during the second and third trimesters. The distribution of expression was determined by in situ hybridization, and each respective tissue is summarized in Tables 1-4. For descriptive purposes, results were grouped by trimester (65-100 d gestation, second trimester; $130-150 \mathrm{~d}$ gestation, third trimester), and are presented below by each parameter (IGF-II, IGFBP-1, IGFBP-3) and organ (liver, kidney, brain, lung).

\section{IGF-II}

Liver. In the fetal liver, IGF-II was abundantly expressed in hepatocytes (Table 1; Fig. 1, $a$ and $b$ ), whereas there was no evidence of expression in the supporting connective tissue nor in the endothelial cells of the arteries, portal vein, or bile ducts. Expression was shown to diminish significantly with advancing gestation.

Kidney. In the fetal kidney, IGF-II mRNA was abundantly expressed in components of the developing kidney derived from the mesenchyme (cells of the developing nephrons, supporting interstitium, Bowman's capsule), whereas there was no evidence of expression in structures derived from the ureteric duct (collecting ducts, ureter) (Table 2; Fig. 4, $a-d$ ). The level of expression observed in the developing kidney diminished significantly with advancing gestation. Moderate levels of IGF-II expression were observed in proximal and distal epithelial cells of the developing nephron, and the visceral and parietal glomerular epithelium displayed abundant expression of IGF-II. In the maturing kidney (130-150 d gestation), parietal epithelial cells and the convoluted tubules expressed significantly lower levels of IGF-II when compared with earlier gestational ages $(65-100 \mathrm{~d})$.

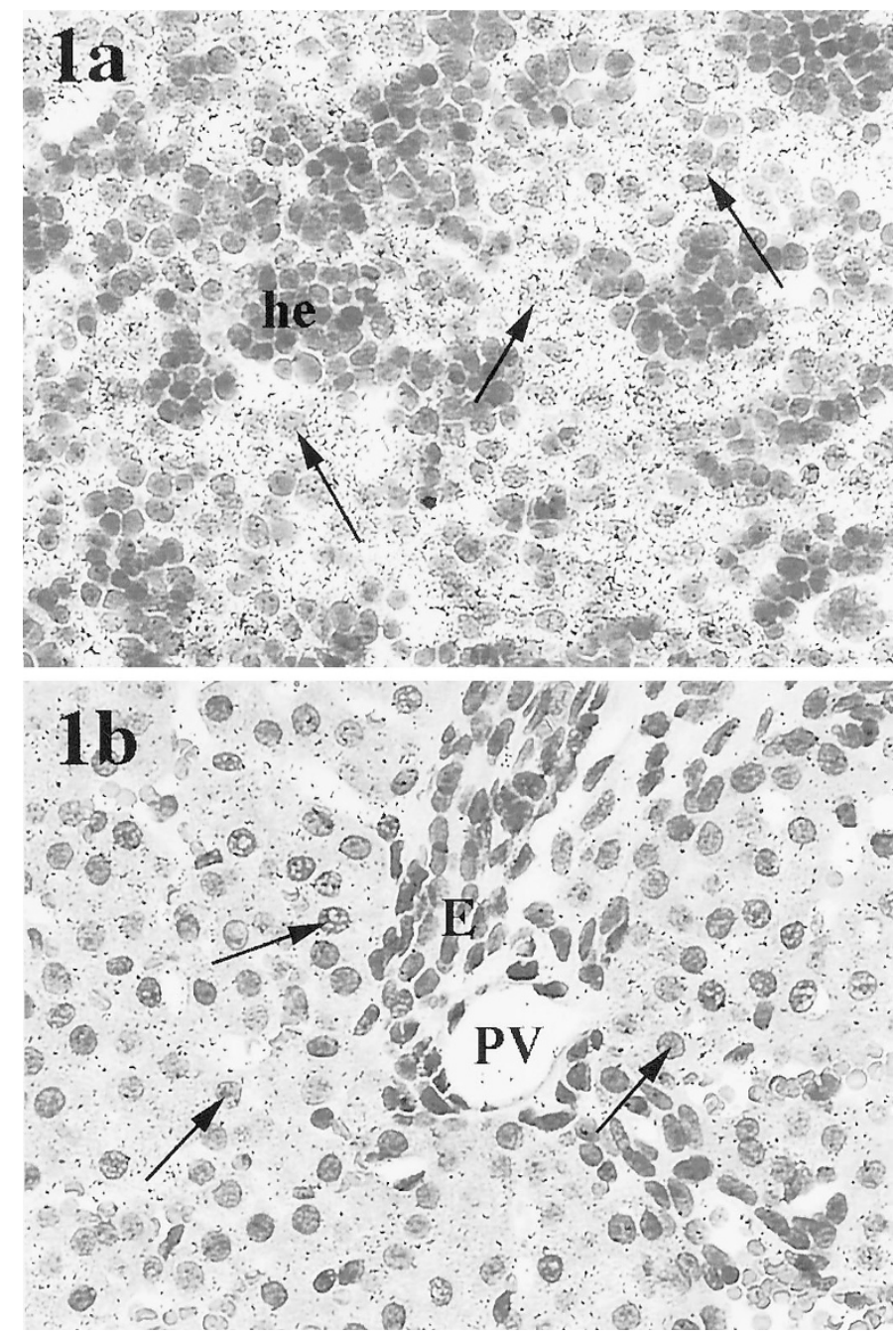

Figure 1. Representative sections of fetal liver at $65(a)$ and $150(b) \mathrm{d}$ gestation-IGF-II. IGF-II mRNA expression was abundant in hepatocytes (arrows). Expression patterns diminished with advancing gestation $(20 \times) . h c$, hematopoietic cells; $E$, epithelial cells; $P V$, portal vein.

Cerebral cortex. Neuroglia, ependyma, choroid plexus, meninges, and capillaries were assessed for IGF-II mRNA expression in the cerebral cortex of the fetal monkey from 65 to $150 \mathrm{~d}$ gestation (Table 3; Fig. 6, $a-c$ ). There was no evidence of IGF-II expression in the neuroglia or in the epithelial lining of the ventricular cavities and ependymal cells throughout gestation. In contrast, there were very high levels of expression in the choroid plexus and meninges, and in the endothelial cells of the capillaries and associated vasculature, which diminished with advancing gestation.

Lung. Respiratory epithelium, lamina propria, submucosa, connective tissue, smooth muscle, cartilage framework, arterial endothelial cells, alveolar epithelium, capillaries, and blood vessels were assessed for IGF-II mRNA expression from 65 to $150 \mathrm{~d}$ gestation (Table 4; Fig. 7, $a-e$ ). The respiratory epithelial cells and the smooth muscle cells of the bronchi expressed low levels of IGF-II. In contrast, the lamina propria, connective tissue, and arterial endothelial cells expressed relatively high levels of IGF-II. In the developing bronchi, IGF-II was mainly expressed in the cells of the cartilage framework and the 

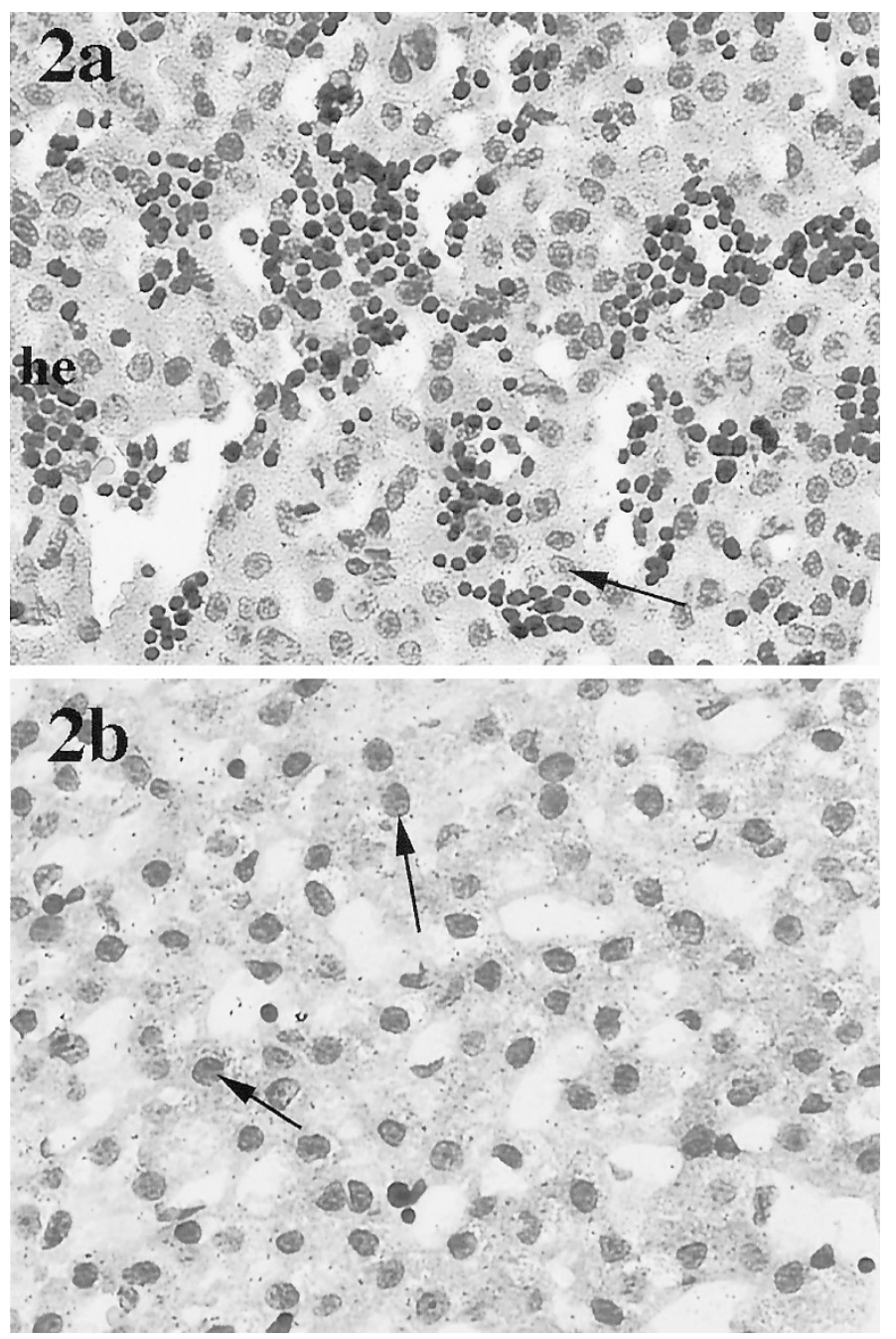

Figure 2. Representative sections of fetal liver at $80(a)$ and $130(b) \mathrm{d}$ gestation-IGFBP-1. IGFBP-1 mRNA expression was low in hepatocytes (arrows). A slight increase with advancing gestation was observed $(20 \times)$.

surrounding connective tissue. Cells lining the submucosa and the mucous glands did not show any evidence of expression, nor did cells of the developing alveoli. The surrounding mesenchymal cells in tissues from the younger fetuses $(65 \mathrm{~d}$ gestation) expressed moderate amounts of IGF-II, and endothelial cells of the developing pulmonary artery expressed high levels of IGF-II. The tunica media and adventitia, which are composed of smooth muscle cells and supporting tissue, expressed very low to no IGF-II. Overall, the level of IGF-II mRNA expression decreased modestly as the fetal lung matured.

\section{IGFBP-1}

IGFBP-1 was expressed only in hepatocytes, although the level of expression was very low (Table 1; Fig. 2, $a$ and $b$ ). In contrast to IGF-II, IGFBP-1 levels increased in the third trimester (130-150 d gestation). IGFBP-1 expression was not observed in any cell types of the fetal kidney, cerebral cortex, or lung (Tables 2-4).

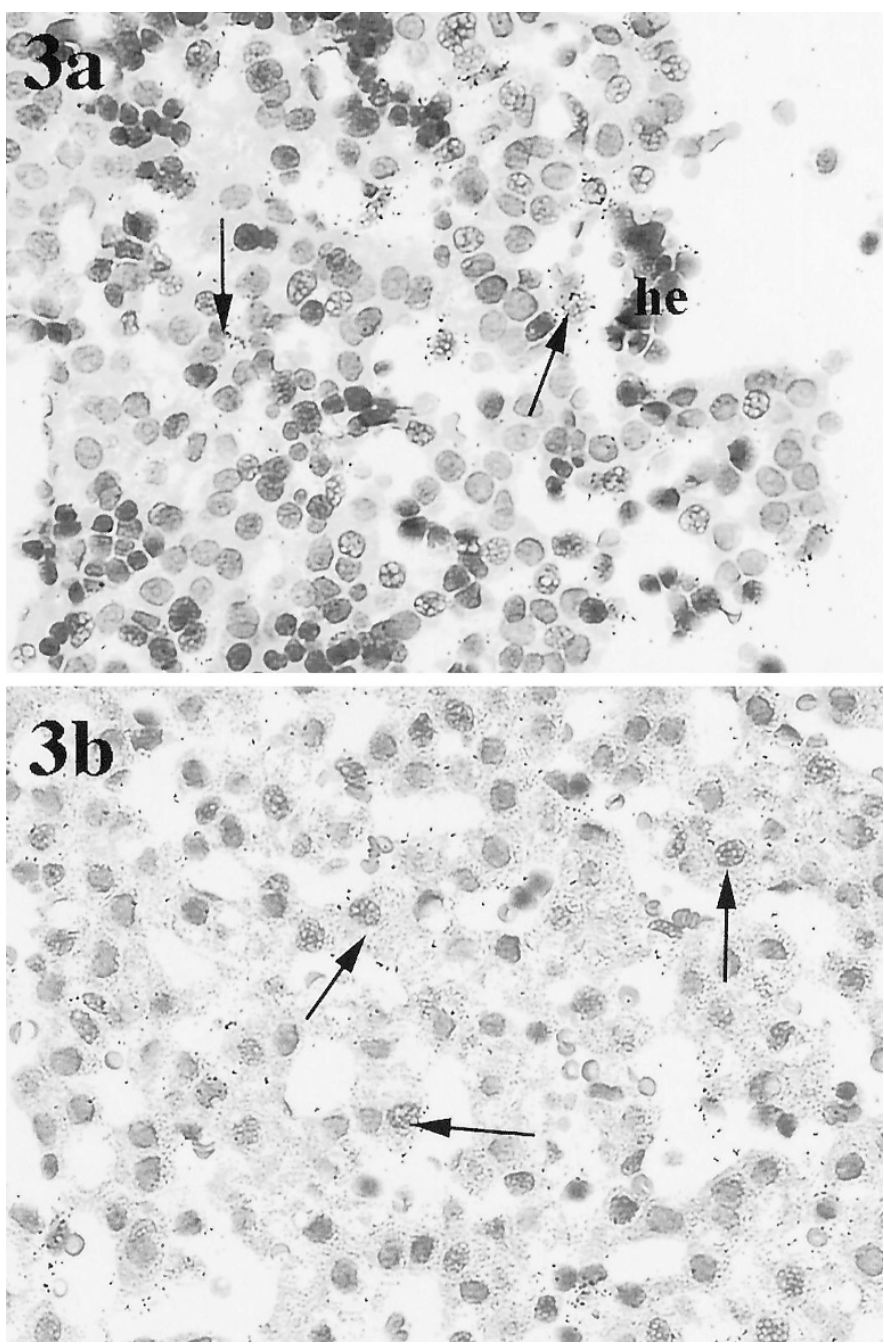

Figure 3. Representative sections of fetal liver at $80(a)$ and $130(b) \mathrm{d}$ gestation-IGFBP-3. IGFBP-3 mRNA expression was modest in hepatocytes (arrows). Expression patterns decreased with advancing gestation $(20 \times) . h c$, hematopoietic cells.

\section{IGFBP-3}

Liver. IGFBP-3 was expressed in hepatocytes, and expression diminished with advancing gestation (Fig. 3, $a$ and $b$ ).

Kidney. The developing nephrons and surrounding supportive mesenchyme expressed high levels of IGFBP-3 during the second trimester only (Table 2; Fig. 5, $a-e$ ). Very high levels of expression were also observed in the capillaries of the developing glomeruli. In contrast to IGF-II, the developing ureter showed high levels of IGFBP-3 in the second trimester. No evidence of IGFBP-3 expression was observed in any of the specimens studied during the third trimester $(130-150 \mathrm{~d}$ gestation).

\section{DISCUSSION}

To assess the role of IGF-II and select IGFBPs in the primate growth process, we have conducted a longitudinal study on the expression of IGF-II, IGFBP-1, and IGFBP-3 genes during the second and third trimesters. Tissues (liver, kidney, cerebral cortex, lung) were collected from rhesus monkey fetuses from 

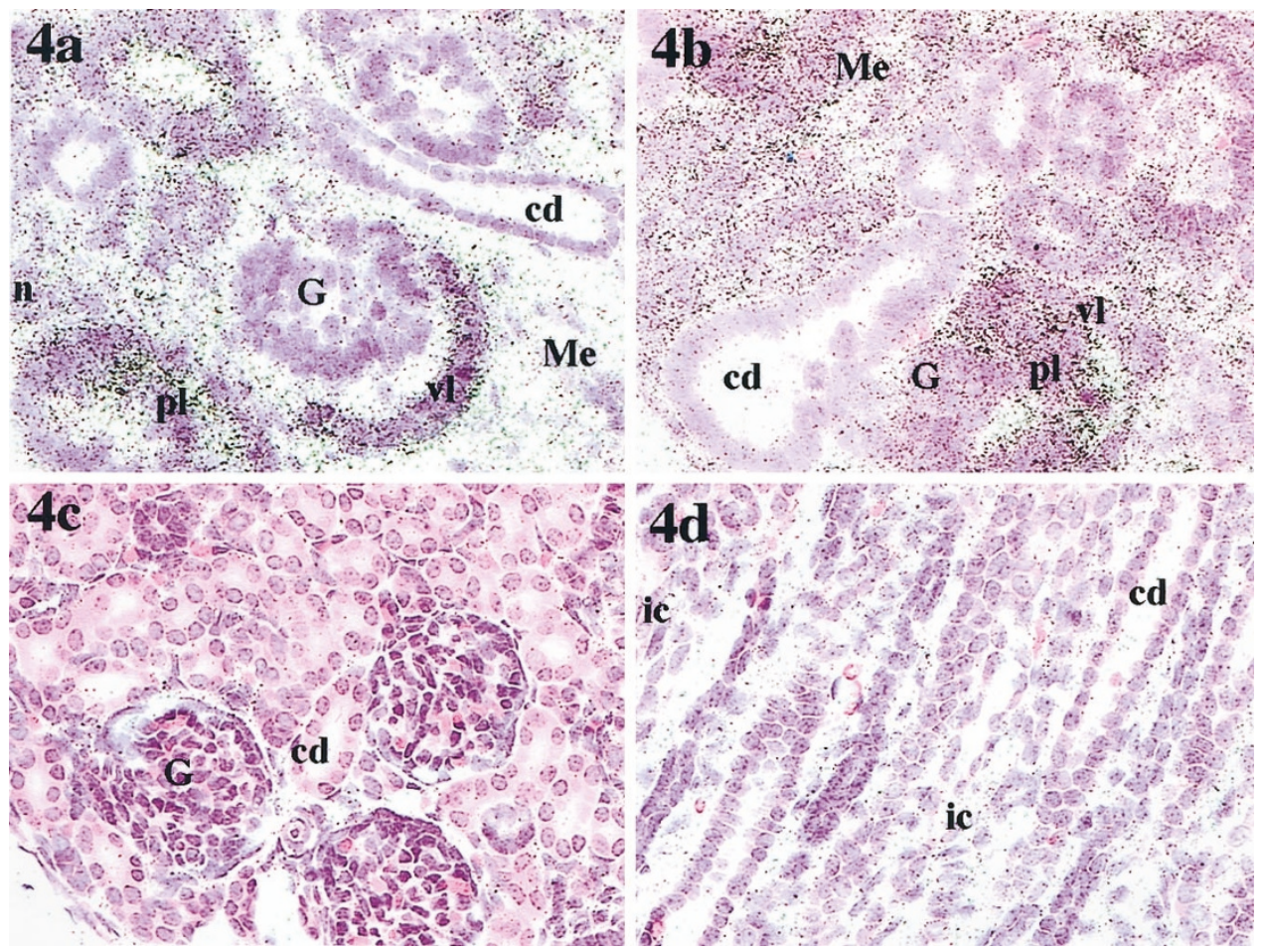

Figure 4. Representative sections of fetal kidney at $65(a), 100(b)$, and $150(c, d)$ d gestation-IGF-II. During the early second trimester (65 d gestation), IGF-II mRNA expression was evident in the developing nephrons $(n)$ and mesenchyme $(M e)$, which decreased with advancing gestation. Note maturing glomerulus $(G)$. There was no evidence of expression in the collecting ducts $(c d)$ at all ages assessed $(20 \times)$. $v l$, visceral layer; $p l$, parietal layer; $i c$, interstitial cells.

gestational d 65-150, then processed for in situ hybridization. Results indicated that IGF-II mRNA was expressed abundantly in fetal monkey tissues similar to the human fetus $(22,25-31)$. The developing monkey fetus expressed a high level of IGF-II mRNAs, particularly during the second trimester, in hepatocytes; maturing glomeruli, supporting mesenchyme, and developing nephrons of the kidney; choroid plexus, meninges, and vasculature of the developing brain; and endothelial cells, connective tissue, lamina propria, and the cartilage framework of the developing lung. In contrast, IGFBP-1 was only modestly expressed in hepatocytes, and IGFBP-3 mRNAs were expressed in hepatocytes, developing nephrons and surrounding supportive mesenchyme, and the developing ureter.

Prior studies have elucidated IGF-II and IGFBP expression in human fetal tissues collected during 8-26 wk gestation (22, $23,25-28,31)$. Assessments of human fetal kidneys between the ages of 8 and $14 \mathrm{wk}$ (late first to early second trimester) have shown that the uninduced metanephric blastema abundantly expressed IGF-II mRNA, whereas the more mature ureteric duct expressed IGFBP-3 mRNA similar to findings in the monkey (31). In the maturing glomerulus, the glomerular epithelial cells and renal mesenchyme of the cortex and medulla expressed IGF-II mRNA, whereas the epithelium of the collecting ducts expressed abundant IGFBP-3. Here, the authors concluded that the specific spatial and temporal pattern of expression of IGFBP genes on the background of abundant IGF-II gene expression suggested that the IGFBP peptides were expressed locally at specific points of nephrogenesis regulating mesenchymal induction, and renal epithelial cell commitment, differentiation, and growth. The human fetal brain and lung have also been shown to express IGF-II in the choroid plexus, endothelial cells, pulmonary arterial endothelium, bronchial cartilage, and bronchiolar epithelium (22), similar to findings in monkeys. These authors also emphasized the crucial role of IGF-II in regulating fetal growth and development. Han et al. (25) analyzed IGFBP mRNAs in human fetal tissues from 10 to 16 wk gestation and found IGFBP-1 was only expressed in fetal liver, and IGFBP-3 mRNAs were localized, overall, to mesenchymal cells. The discrepancy between the cellular sites of IGF-II synthesis and accumulation has been explained by the ability of IGFBPs to sequester and maintain IGF at defined anatomical locations (30). The authors of these data suggested a redistribution of IGFs away from their sites of synthesis to sites of action.

In the studies described herein, IGF-II mRNA gene expression was much higher in the cells of the developing nephrons, and developing visceral and parietal layers, when compared with vasculature or the ureters of the developing kidney. Lamina propria, cartilage framework, and arterial endothelial cells also showed higher expression of IGF-II mRNA expression than alveoli epithelium, smooth muscle, or capillaries of the developing lung. The developing nephrons, visceral and parietal layers of the kidney; hepatocytes; lamina propria, cartilage framework, and arterial endothelial cells of the lung all undergo a high degree of cellular differentiation and proliferation during the second trimester. The high levels of IGF-II expression at this stage of fetal development in these cells and tissues suggests that IGF-II functions as an autocrine and paracrine growth factor for differentiation and proliferation at these sites, similar to human fetuses. IGFs are clearly potent 

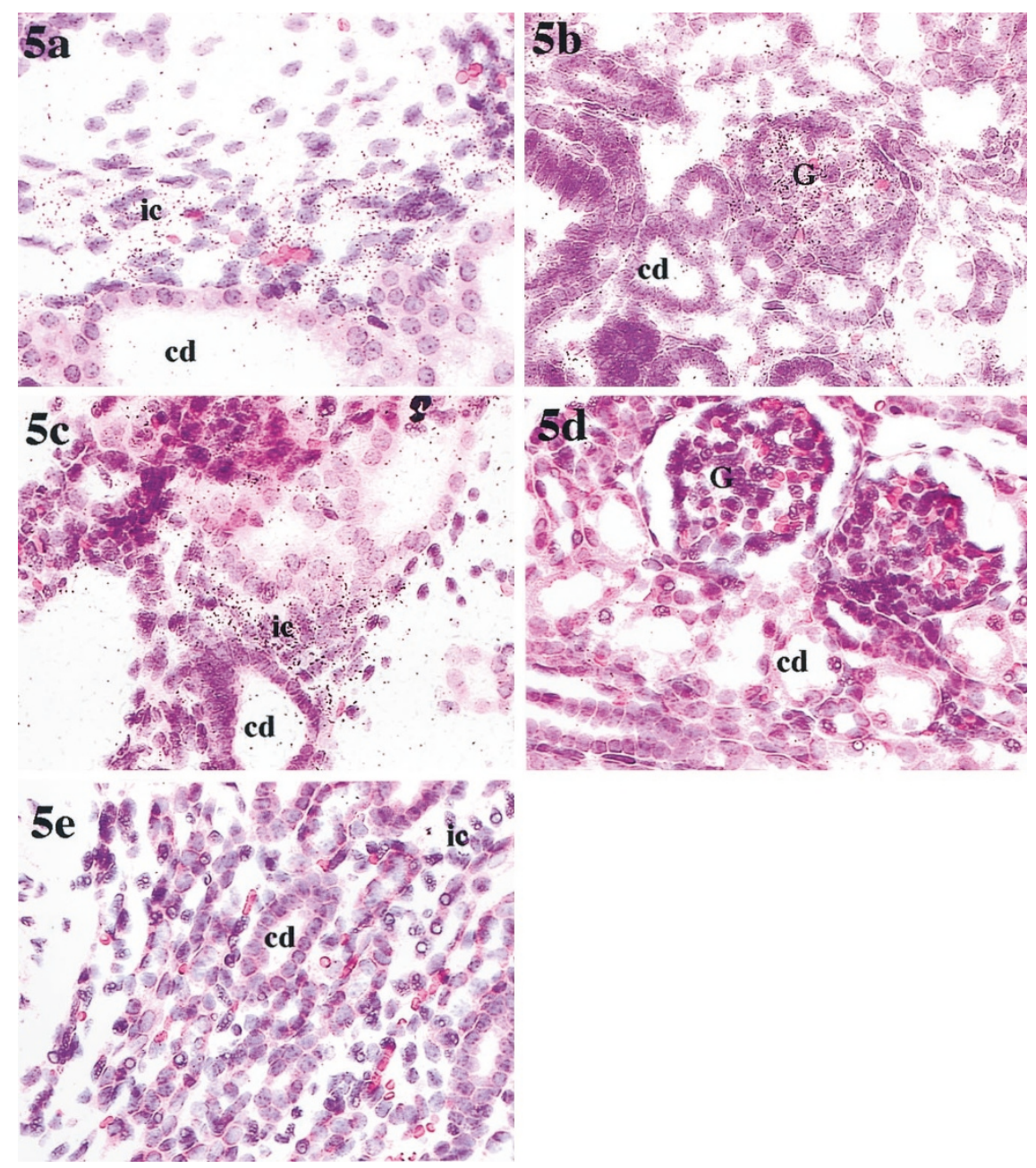

Figure 5. Representative sections of fetal kidney at $80(a-c)$ and $150(d, e)$ days gestation-IGFBP-3. During the second trimester (80 d gestation), IGFBP-3 expression was evident in the developing glomerulus $(G)$ and mesenchyme $(M e)$, which decreased with advancing gestation $(20 \times)$. $c d$, collecting duct; $i c$, interstitial cells.

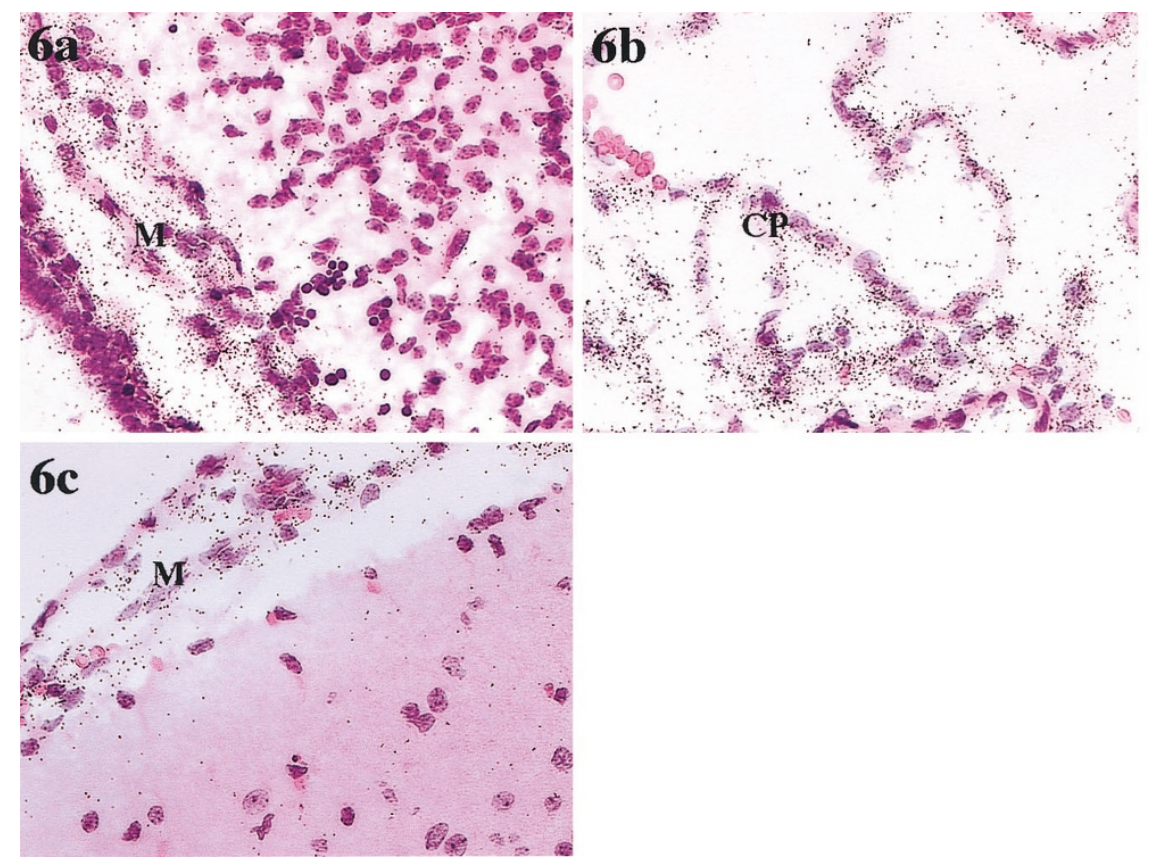

Figure 6. Representative sections of the fetal brain (cerebral cortex) at $65(a)$ and $150(b, c)$ days gestation-IGF-II. High levels of IGF-II expression were found in the choroid plexus $(C P)$ and meninges $(M)$, which diminished with advancing gestation; there was no evidence of expression in the parenchyma (20×). 

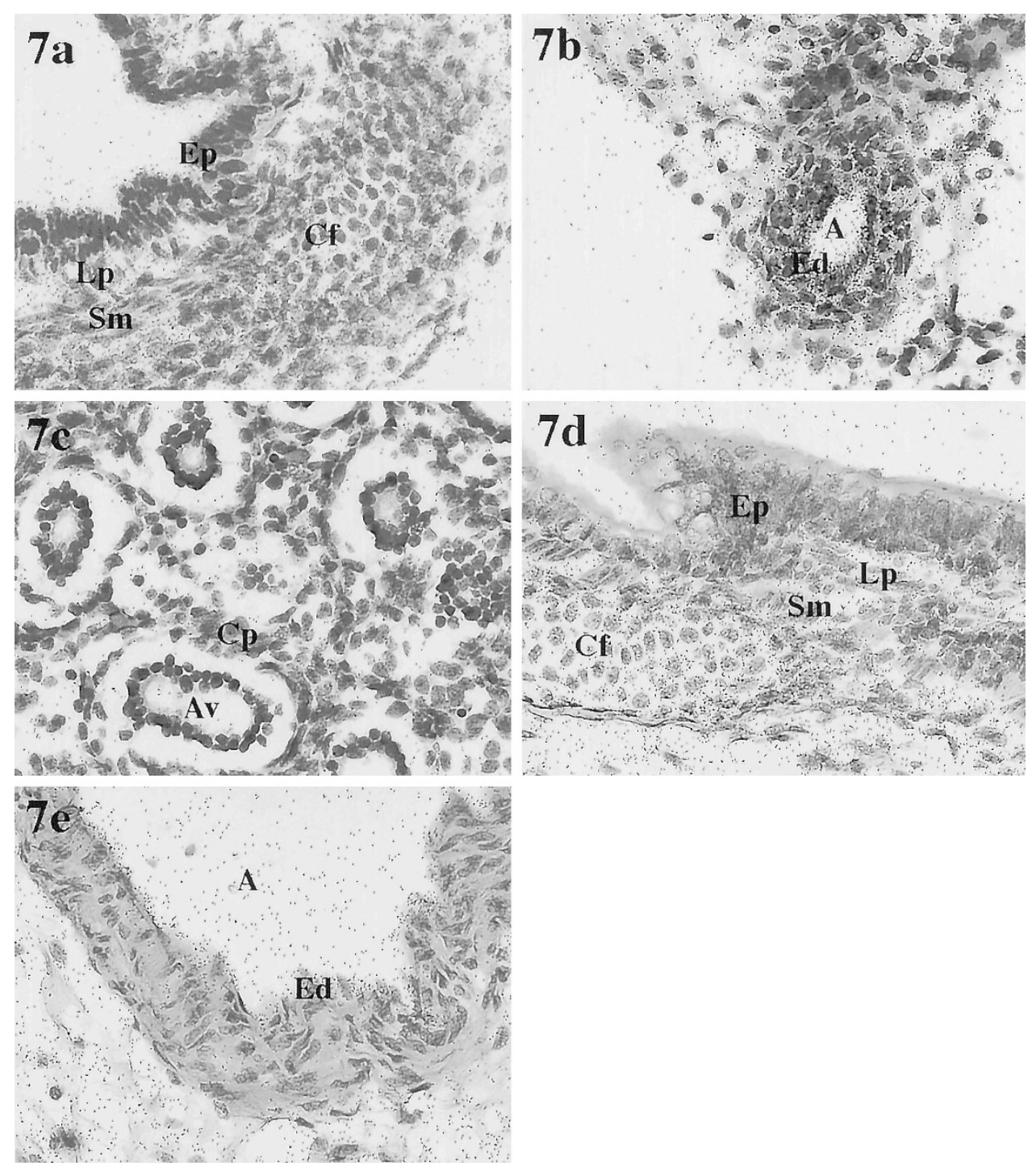

Figure 7. Representative sections of fetal lung at $65(a-c), 110(d)$, and $150(e)$ days gestation-IGF-II. Epithelial cells $(E p)$, cartilage $(C f)$, and smooth muscle $(S m)$ of the bronchi expressed low levels of IGF-II. In contrast, the lamina propria $(L p)$, connective tissue, and arterial endothelial cells $(E d)$ expressed relatively high levels of IGF-II. Alveoli $(A v)$ showed no or low expression of IGF-II. Expression decreased modestly over time $(20 \times)$. $C p$, capillaries.

mitogenic and differentiation-promoting factors (7) that regulate the development and growth of undifferentiated fetal tissues as shown in these studies. As noted above, the functions of IGFBPs include localizing IGFs to specific cell types, and modulating growth-promoting actions (12), therefore the presence of IGFBP-3, for example, in the fetal kidneys suggests the importance of the IGFBPs during development of this organ system.

Differences in IGF-II gene expression in human fetal liver have been reported $(22,26,27)$. Birnbacher et al. (22) showed high levels of expression of IGF-II in hepatocytes similar to findings in fetal monkeys described here using a nearly fulllength IGF-II cDNA probe. Han et al. (26) used a 31nucleotide IGF-II oligomer, and reported no expression of IGF-II in hepatocytes, although expression was observed in perisinusoidal cells. We used 150-bp complementary RNA probes that were labeled with ${ }^{35}$ S-rUTP, which showed high sensitivity for detection of cellular mRNAs. The cell types identified indicated high specificity for IGF-II mRNA expres- sion with low background, suggesting that the 150-bp complementary RNA probes were sufficiently sensitive to detect the expression of IGF-II mRNA in fetal tissues. Although Birnbacher et al. (22) suggested that different probes may alter detection of the pattern of IGF-II expression in tissues, our findings were similar when using a nearly full-length IGF-II cDNA probe.

In both human and nonhuman fetal primates, serum IGF levels have been shown to increase with advancing gestation $(1,16,33-35)$, and alterations in this developmental profile have been correlated with abnormal growth patterns $(19,20$, $36,37)$. In situ hybridization studies provide essential information on the localization of IGF gene expression to specific fetal cell types, thus providing greater insight into the role of the IGF system during development $(38,39)$. The studies described here help to fill a gap in knowledge of the role of the IGF system in primates because of the lack of availability of human fetal specimens during the course of gestation. Intrauterine growth restriction (IUGR) remains a significant pedi- 
atric problem and a major cause of perinatal morbidity and mortality. To prevent and/or correct IUGR before irreversible damage is done $(40,41)$, specific mechanisms and interactions that regulate fetal growth must be known. Because of the close similarities between humans and monkeys developmentally and physiologically, further studies with the fetal monkey will provide essential information on the role of the IGF system in fetal health and disease, and will be crucial for the identification of novel therapies for treating compromised human fetuses in utero.

Acknowledgments. The authors thank Drs. C. Plopper and D. Matsell for review of the manuscript.

\section{REFERENCES}

1. Chard T 1994 Insulin-like growth factors and their binding proteins in normal and abnormal human fetal growth. Growth Regul 4:91-100

2. Hill DJ, Petrik J, Arany ER 1998 Growth factors and the regulation of fetal growth Diabetes Care 21:B60-B69

3. O'Dell SD, Day IN 1998 Insulin-like growth factor II (IGF-II). Int J Biochem Cell Biol 30:767-771

4. DeChiara TM, Efstratiadis A, Robertson EJ 1990 A growth-deficiency phenotype in heterozygous mice carrying an insulin-like growth factor II gene disrupted by targeting. Nature 345:78-80

5. Liu J-P, Baker J, Perkins AS, Robertson EJ, Efstratiadis A 1993 Mice carrying null mutations of the genes encoding insulin-like growth factor 1 (Igf-1) and type 1 IGF receptor (Igflr). Cell 75:59-72

6. Woods KA, Comacho-Hubner C, Barter D, Clark AJ, Savage MO 1997 Insulin-like growth factor I gene deletion causing intrauterine growth retardation and severe short stature. Acta Paediatr Suppl 423:39-45

7. Han VKM, Hill DJ 1992 The involvement of insulin-like growth factors in embryonic and fetal development. In: Schonfield P (ed) The Insulin-like Growth Factors: Structure and Biological Functions. Oxford University Press, New York, pp 178-220

8. Rosen CJ 1999 Serum insulin-like growth factors and insulin-like growth factorbinding proteins: clinical implications. Clin Chem 45:1384-1390

9. Jones J, Clemmons DR 1995 Insulin-like growth factors and their binding proteins: biological actions. Endocr Rev 16:3-34

10. Hwa V, Oh Y, Rosenfeld RG 1999 The insulin-like growth factor-binding protein (IGFBP) superfamily. Endocr Rev 20:761-787

11. Westwood M 1999 Role of insulin-like growth factor binding protein 1 in human pregnancy. Rev Reprod 4:160-167

12. Clemmons DR 1993 IGF binding proteins and their functions. Mol Reprod Dev 35:368-375

13. Albiston AL, Herington AC 1992 Tissue distribution and regulation of insulin-like growth factor (IGF)-binding protein-3 messenger ribonucleic acid (mRNA) in the rat: comparison with IGF-I mRNA expression. Endocrinology 130:497-502

14. Tanimura T, Tanioka Y 1975 Comparison of embryonic and foetal development in man and rhesus monkey. In: Breeding Simians for Developmental Biology, Laboratory Animal Handbook 6:205-233

15. Tarantal AF 1993 Hematologic reference values for the fetal long-tailed macaque (Macaca fascicularis). Am J Primatol 29:209-219

16. Tarantal AF, Gargosky SE 1995 Characterization of the insulin-like growth factor axis in the fetal macaque (Macaca mulatta and Macaca fascicularis): a crosssectional study. Growth Regul 5:190-198

17. Tarantal AF, Hendrickx AG 1988 Prenatal growth in the cynomolgus and rhesus macaque (Macaca fascicularis and Macaca mulatta) - a comparison by ultrasonography. Am J Primatol 15:309-323

18. Tarantal AF, Hunter MK, Gargosky SE 1997 Direct administration of insulin-like growth factor to fetal rhesus monkeys (Macaca mulatta). Endocrinology 138:33493358
19. Tarantal AF, Marthas ML, Gargosky SE, Otsyula M, McChesney MB, Miller CJ, Hendrickx AG 1995 Effects of viral virulence on intrauterine growth in SIV-infected fetal rhesus macaques (Macaca mulatta). J AIDS Hum Retrovirol 10:129-138

20. Tarantal AF, Gargosky SE, Ellis DS, O’Brien Jr WD, Hendrickx AG 1995 Hematologic and growth-related effects of frequent prenatal ultrasound exposure in the long-tailed macaque (Macaca fascicularis). Ultrasound Med Biol 21:1073-1081

21. Tarantal AF, Salamat SS, Britt WJ, Luciw PA, Hendrickx AG, Barry PA 1998 Neuropathogenesis induced by rhesus cytomegalovirus in fetal rhesus monkeys (Macaca mulatta). J Infect Dis 177:446-450

22. Birnbacher R, Amann G, Breitschopf H, Lassmann H, Suchanek G, Heinz-Erian P 1998 Cellular localization of insulin-like growth factor II mRNA in the human fetus and the placenta: detection with a digoxigenin-labeled cRNA probe and immunohistochemistry. Pediatr Res 43:614-620

23. Delhanty PJD, Hill DJ, Shimasaki S, Han VKM 1993 Insulin like growth factor binding protein- $4,-5$, and -6 mRNAs in the human fetus: localization to sites of growth and differentiation. Growth Regul 3:8-11

24. Funk B, Kessler U, Eisenmenger W, Hansmann A, Kolb HJ, Kiess W 1992 The expression of insulin-like growth factor binding proteins is tissue specific during human fetal life and early infancy. Acta Endocrinol 127:107-114

25. Han VKM, Bassett N, Walton J, Challis JRG 1996 The expression of insulin-like growth factor (IGF) and IGF binding protein (IGFBP) genes in the human placenta and membranes: evidence for IGF-IGFBP interactions at the fetomaternal interface. J Clin Endocrinol Metab 81:2680-2693

26. Han VKM, D'Ercole AJ, Lund PK 1987 Cellular localization of somatomedin (insulin-like growth factor) messenger RNA in the human fetus. Science 236:193-197

27. Han VKM, Hill DJ, Strain AJ, Towle AC, Lauder JM, Underwood LE, D'Ercole AJ 1987 Identification of somatomedin/insulin-like growth factor immunoreactive cells in the human fetus. Pediatr Res 22:245-249

28. Han VKM, Lund PK, Lee DC, D'Ercole AJ 1988 Expression of somatomedin/IGF mRNAs in the human fetus: identification, characterization, and tissue distribution. J Clin Endocrinol Metab 66:422-429

29. Hill DJ, Clemmons DR 1992 Similar distribution of insulin-like growth factor binding proteins-1, -2, -3 in human fetal tissues. Growth Factors 6:315-326

30. Hill DJ, Clemmons DR, Wilson S, Han VKM, Strain AJ, Milner RDG 1989 Immunological distribution of one form of insulin-like growth factor (IGF)-binding protein and IGF peptides in human fetal tissues. J Mol Endocrinol 2:31-38

31. Matsell DG, Delhanty PJD, Stepaniuk O, Goodyer C, Han VKM 1994 Expression of insulin-like growth factor and binding protein genes during nephrogenesis. Kidney Int 46:1031-1042

32. Coulter CL, Han VKM 1996 The pattern of expression of insulin-like growth factor (IGF), IGF-I receptor and IGF binding protein (IGFBP) mRNAs in the rhesus monkey placenta suggests a paracrine mode of IGF-IGFBP interaction in placental development. Placenta 17:451-460

33. Giudice LC, de Zegher F, Gargosky SE, Dsupin BA, de las Fuentes L, Crystal RA, Hintz RL, Rosenfeld RG 1995 Insulin-like growth factors and their binding proteins in the term and preterm human neonate with normal and extremes of intrauterine growth. J Clin Endocrinol Metab 80:1548-1555

34. Langford K, Nicolaides K, Miell JP 1998 Maternal and fetal insulin-like growth factors and their binding proteins in the second and third trimesters of human pregnancy. Hum Reprod 13:1389-1393

35. Liu F, Powell DR, Styne DM, Hintz RL 1991 Insulin-like growth factors (IGF) and IGF-binding proteins in the developing rhesus monkey. J Clin Endocrinol Metab 72:905-911

36. Holmes R, Montemagno R, Jones J, Preece M, Rodeck C, Soothill P 1997 Fetal and maternal plasma insulin-like growth factors and binding proteins in pregnancies with appropriate or retarded fetal growth. Early Hum Dev 49:7-17

37. Lassarre C, Hardouin S, Daffos F, Forestier F, Frankenne F, Binoux M 1991 Serum insulin-like growth factors and insulin-like growth factor binding proteins in the human fetus. Relationships with growth in normal subjects and in subjects with intrauterine growth retardation. Pediatr Res 29:219-225

38. Matsell DG, Bennett T, Armstrong RA, Goodyer P, Goodyer C, Han VKM 1997 Insulin-like growth factor (IGF) and IGF binding protein gene expression in multicystic renal dysplasia. J Am Soc Nephrol 8:85-94

39. Miyazaki E, Ohshiro K, Taira Y, Puri P 1998 Altered insulin-like growth factor mRNA expression in human hypoplastic lung in congenital diaphragmatic hernia. J Pediatr Surg 33:1476-1479

40. Barker DJP 1999 Fetal origins of cardiovascular disease. Ann Med 31:3-6

41. Hales CN 1997 Fetal and infant growth and impaired glucose tolerance in adulthood: the "thrifty phenotype" hypothesis revisited. Acta Paediatr Suppl 422:73-77 